\title{
Spatial Disparities of Senior Secondary Educational Attainment in Haryana
}

\author{
Anita $^{1}$ and Vijay Wanti ${ }^{2}$ \\ ${ }^{1}$ Ph.D (J.N.U. New Delhi), Associate Prof., Deptt. Of Geography, Dronacharya Govt. \\ College, Gurugram, Haryana \\ ${ }^{2}$ Associate Prof., Deptt. Of Geography, D.A.V. Centenary College, Faridabad, Haryana
}

\section{ARTICLE INFO}

\section{Keywords:}

Education

Educational Level

Educational Attainment

Senior Secondary

Education Attained

\begin{abstract}
For development of human resources of a nation and to harness their full potential throughout their life, education of all human beings is of great importance. It is the process of teaching, learning and training skills which prepares them for successful life. Secondary Education though not "fundamental right" of people, yet government and society understand it important for prosperity and good health of its people. It is a link between secondary and higher education after which specialisation in the fields of education starts. It is a postSecondary education.

To provide it, a number of schemes, policies, programs have been framed from time to time by the government. Action plan included gender sensitisation to minimise the gender gap in educational attainment spatial disparities and in sequence monitored at various levels from time to time with the help of public and private agencies. Nonetheless, gender disparities are nearly universal in terms of educational attainment at each level. In the present study, Senior Secondary education has been selected as focus. It is a micro level study based on census 2011 data. Maps are prepared using GIS technology to analyse patterns of Senior Secondary education attained total population and in males and females separately at district level of Haryana.
\end{abstract}

\section{Introduction}

Level of education is one of the basic indicators of the level of development achieved by a society. Communication, Industrialisation and Commerce grows horizontally and vertically with the spread of education. Education is an important input in overall development of individuals enabling them to comprehend their social, political and cultural environment better and respond to it appropriately. It acts as a catalyst for social upliftment enhancing the returns on investment made in almost every aspect of development effort, be it population control, health, hygiene, environmental degradation control, employment of weaker sections of the society.

Senior Secondary education level is the level after which Senior secondary education attained population decides direction for specialisation or drops further education for entry into jobs. To provide it, a number of schemes, policies, programs have been framed from time to time by the government. Action plan included gender sensitisation to minimise the gender gap in educational attainment spatial disparities and in sequence monitored at various levels from time to time with the help of public and private agencies.

* Corresponding Author E-Mail Address: anita.gurgaon@Yahoo.co.in 
Education - Education is the process of teaching, learning, training skills to human beings to prepare them for successful individual and social life. There have been different traditional and modern ways in India and in other countries of the world but the aim is common; i.e., preparation of better human resource and capital.

Educational Level -The Educational level refers to the highest educational level attained by a person. A person who is studying in a particular level but has not yet completed it, is classified with reference to the immediate lower educational level attained. In the case of a person who holds both general and technical qualifications, either of equivalent or at varying levels, both these qualifications have been recorded. (Census of India 1981).

Educational attainment - Educational attainment is generally measured by the percentage distribution of various levels of educational attainment in the literate population above the age of 10 or 15 . As sizable percentage of literates do not under go for education below this age. Only the formal courses actually passed are counted as educationally attained (Census of India 2011)

Senior Secondary Education Level - It is postsecondary education level passed from schools after completion of secondary education in the schools.

\section{Need of the Study}

Senior secondary education level is not a compulsory education like primary and elementary education level; therefore, it is important to see the spatial distribution of the percentage of Senior secondary education level attained population in Haryana. It is important to know the proportion of the population which recognised the need, importance and value of Senior secondary education level. They could understand that Senior Secondary educational attainment would put them in the category of higher order human capital. It would help them in getting higher order jobs with better income packages than secondary education level as it would be essential qualification for those job opportunities. It would also affect their performance during career. Hence, despite being optional, they attained Senior secondary educational certificate.

Bhende and Kanetkar (2001) write: literacy and level of educational attainment are important indicators of social development. They affect demographic behaviour concerning marriage, fertility, mortality, migration as well as participation in labour force. In a number of researches, a clear-cut negative relationship has been established between the educational level of women and their fertility. But, at the same time, positive relationship has been found between the age of marriage and level of educational attainment.

Jayashree (2003) analysed the implications of female education and rights in her article that woman with higher education, prestigious occupation and high income have higher life expectancy. There is a common feeling that elderly women of the coming decades will be quite educated, more literate, exposed to outer world, have urban experiences, financially independent, economically sound etc. Therefore, their higher longevity will not cause problems even if they become widows. It is pure illusion that woman folk who have all the above features belong to middle class and adopt small family norms as a result they have few adult children. Hence, in old age, they are left alone by their limited care takers. They may not face acute financial problems but they do have to suffer from loneliness, frustration, helplessness, emotional stability and insecurity along with other common aging elements and disability.

The relationship between level of education attained and sector of employment is diverse and it has changed over time. Having attainment of Senior Secondary Education has become increasingly important in the trade sector and to lesser extent in services. In sectors where important proportion of employed women are concentrated, having Senior Secondary education and above seems to play an increasingly important role in ensuring access to these employment opportunities. Women's employment in Indinesia Page 249. Transformation of 
Women at Work in Asia: An Unfinished Development Agenda edited by Sukti Dasgupta, Sher Singh Verick, 26sept,2016SAGE PUBLISHING INDIA -Business and Economics.

\subsection{Geographical Location and Background}

Haryana is located in the North Western part of India. Its latitudinal extent is from $27^{\circ} 39^{\prime}$ North latitude to $30^{\circ} 55.5^{\prime}$ North latitude and longitudinal extent is from $74^{\circ} 27.8^{\prime} \mathrm{E}$ to $77^{\circ} 36.5^{\prime} \mathrm{E}$. With total area of 44,212 sq. km, it is one of the small states of India. As physical boundary, Yamuna river, separates it from Uttara Khand and Uttar Pradesh on Eastern side. Shivalik's foothills of Himalaya on the Northern side. Aravalli hills in the south. Periphery of Thar desert on the west. As administrative boundaries, Himachal Pradesh touches it on Northern side and Punjab on North Western side. Rajasthan lies on Western and Southern side. Haryana has common boundary with Delhi on the south. Delhi is surrounded by Haryana on three sides. It came into existence on $1^{\text {st }}$ November, 1966 as $17^{\text {th }}$ state of India, with 7 districts namely, Hisar, Rohtak, Karnal, Ambala, Gurgaon and Mahendergarh and Jind.

On 15 January, 2007, Haryana had 4 division, 20 districts, 47 sub-divisions, 67 tehsils, 46 sub tehsils, 119 blocks, 106towns, 6955villages (Statistical Abstract of Haryana, 2005-6 pg.23,29). In 2011, administrative divisions increased to 21 districts. Chandigarh located in the north is the capital of Haryana.

Physiography wise, Haryana can be divided into seven regions.

1. Shivalik's

2. Piedmont plains

3. Alluvial Plains

4. Plain with Sand Dunes

5. Flood Plains

6. Riverhills

7. The Undulating Sandy Plain.

Yamuna and Gagger are two main rivers. Apart from these Sahabi and Dohan flows.

Haryana has Semi-Arid, Continental, Monsoon climate. May - June are the hottest months when temperature rises to $45^{\circ}$ to $48^{\circ} \mathrm{Celsius.} \mathrm{January} \mathrm{and} \mathrm{December} \mathrm{are} \mathrm{coldest} \mathrm{months} \mathrm{when}$ temperature falls up to $\mathrm{O}^{\circ} \mathrm{C}$. Loo (hot dusty winds) remains a feature during summers like climate and relief.

There are varied types of soils.

Very Light, light (sandy loam), Medium Soils (Light Loam), The Moderately Heavy Soil (Khaddar), Heavy and Very heavy Soil (Bet), Rocky Surface Soils.

Poor in minerals except in Mahendergarh district some iron ore, mica, lime stone.

Haryana has agrarian economy.

For Senior School Education, were recognized institutions (Statistical Abstract of Haryana,2005-6 pg. 107)

23,258 km Road length, 4047.80 route in kms (Statistical Abstract of Haryana,2005-6 pg.461,473)

\subsection{Research Questions}

How percentage wise district-wise Senior secondary education attained population is spatially distributed in Haryana? How percentage wise district-wise Senior secondary education attained male and female population is distributed across the state?

\subsection{Data Base}

The study is based on district and state level Secondary data -Registrar General of India, Census of India. 


\section{Methodology}

Both quantitative and qualitative methods of social science research have been used for this study. GIS technology has been used to prepare choropleth maps showing percentagewise data for Senior secondary education attained population in the age-group of 18-24 years for total, male and female population of Haryana for spatial analysis.

\subsection{Analysis for Inter-District variations among Senior Secondary Education Attained}

In in 18-24 years age-group. But district wise, it was unevenly distributed across the state. Census 2011 data, Haryana had shown average 27.1 percent total population, 29.3 percent male population and 24.6 percent female population as Senior Secondary Education attained population

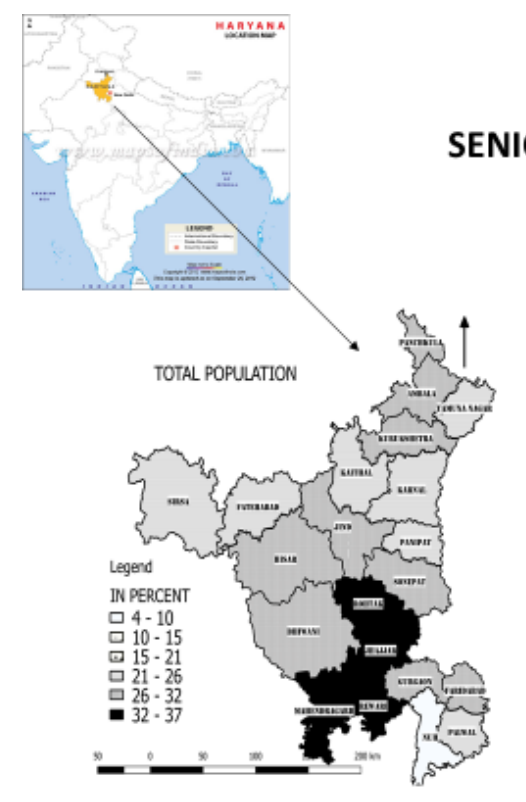

\section{HARYANA \\ SENIOR SECONDARY EDUCATION ATTAINED POPULATION AGE GROUP - 18-24 YEARS}

2011
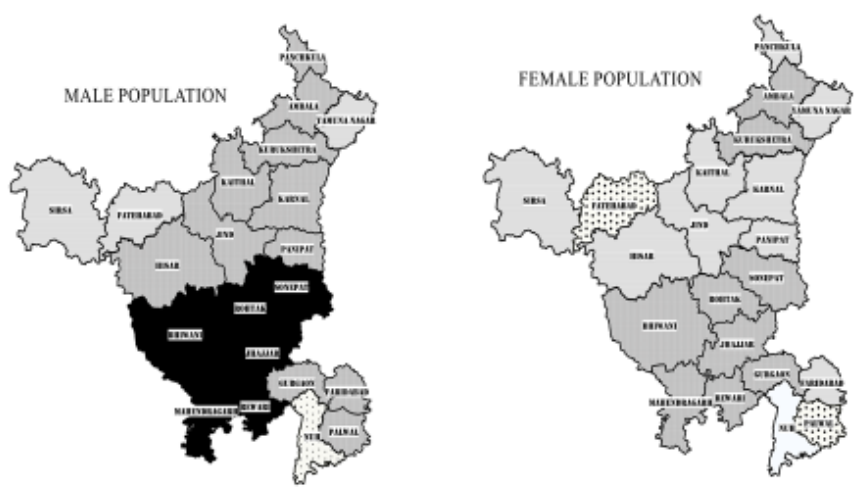

CENSUS OF INDIA-2011

There was wide range of variation from lowest 4.5 percent educational attainment among female population in Mewat (Nuh) district to highest 37.4 percent among male population of Mahendergarh district at Senior Secondary Education level in Haryana. These variations were found in male female population separately as well in 18 to 24 years of age-group. In all the districts, females had less than 31.3 percent Senior Secondary Education attained population. Only 7 districts out of 21 total districts of Haryana in 2011; namely Bhiwani, Mahendergarh, Rewari, Jhajjar, Gurgaon, Rohtak, and Sonipat had more than Haryana state average 27.1 percent Senior Secondary Education attained female population. Eight districts namely, Sirsa, Fatehabad, Kaithal, Yammunanagar, Karnal, Panipat, Palwal and Mewat (Nuh) had less than the State Female Senior Secondary Education attained population; i.e.24.6 percent. 
Table 1.

Haryana, Senior Secondary Educational Attainment in Percentage, 18- 24 years Age-group, 2011

\begin{tabular}{clccc}
\hline Sr. No. & State/District & Total & Male & Female \\
\hline $\boldsymbol{0}$ & HARYANA & $\mathbf{2 7 . 1}$ & $\mathbf{2 9 . 3}$ & $\mathbf{2 4 . 6}$ \\
1 & Jhajjar & $\mathbf{3 4 . 5}$ & $\mathbf{3 7 . 2}$ & $\mathbf{3 1 . 3}$ \\
2 & Mahendragarh & $\mathbf{3 3 . 3}$ & $\mathbf{3 7 . 4}$ & $\mathbf{2 8 . 5}$ \\
3 & Rewari & $\mathbf{3 3}$ & $\mathbf{3 6}$ & $\mathbf{2 9 . 8}$ \\
4 & Rohtak & $\mathbf{3 2 . 2}$ & $\mathbf{3 3 . 8}$ & $\mathbf{3 0 . 3}$ \\
5 & Sonipat & $\mathbf{3 1 . 1}$ & $\mathbf{3 3}$ & $\mathbf{2 8 . 8}$ \\
6 & Bhiwani & $\mathbf{3 0 . 5}$ & $\mathbf{3 3 . 5}$ & $\mathbf{2 6 . 8}$ \\
7 & Gurgaon & $\mathbf{2 8 . 8}$ & $\mathbf{2 9 . 9}$ & $\mathbf{2 7 . 3}$ \\
8 & Kurukshetra & $\mathbf{2 8 . 8}$ & $\mathbf{3 0 . 6}$ & $\mathbf{2 6 . 7}$ \\
9 & Jind & $\mathbf{2 8 . 1}$ & $\mathbf{3 0 . 9}$ & 24.5 \\
10 & Ambala & $\mathbf{2 8}$ & 29 & $\mathbf{2 6 . 8}$ \\
11 & Hisar & $\mathbf{2 8}$ & $\mathbf{3 0 . 3}$ & $\mathbf{2 5 . 1}$ \\
12 & Faridabad & 27.4 & 29.2 & $\mathbf{2 5 . 2}$ \\
13 & Panchkula & 26.9 & 27.9 & $\mathbf{2 5 . 7}$ \\
14 & Kaithal* & 26.3 & 29.2 & 22.9 \\
15 & Panipat & 25.4 & 27.1 & 23.4 \\
16 & Karnal & 25.3 & 26.9 & 23.4 \\
17 & Yamunanagar* & 24.3 & 24 & $24.5 *$ \\
18 & Fatehabad & 22.8 & 24.8 & 20.4 \\
19 & Sirsa & 22.6 & 23.4 & 21.6 \\
20 & Palwal & 21.9 & 26.9 & 16 \\
21 & Mewat & 8 & 11.2 & 4.5 \\
\hline
\end{tabular}

* District with marginally higher female educational attainment than males at Sr. Secondary Level. Source: Census of India 2011

\section{Findings}

1. Though Gurugram and Nuh were adjacent districts but still Nuh district had the lowest percentage $(4.5 \%)$ among female Senior secondary education attained population and Gurugram district had 27.2 percentage of Senior Secondary Education Attained female population.

2. Except Yammunanagar, females were educationally backward across the state as compared to males at Senior Secondary Education Attainment level in 18-24 years age-group. In Yammunanagr, females were marginally ahead by 0.5 percent though Yammunagar was not a star district at overall Senior Secondary Education Attainment level.

3. Except Nuh, where Senior Secondary Education percentage was just 8 percent, total population without division in males and female category had attained 21.9 percent Senior Secondary Education level. On dividing male and female population district-wise in Haryana leaving Nuh apart, minimum percentage was at least 16 percent at Senior Secondary Education level in 18-24 years age-group.

4. All the districts around National Capital Delhi, namely Sonepat, Rohtak, Jajjar, Gurgaon and Faridabad had attained above 27.4 percent. Among these four districts Faridabad district had attained lowest percentage $(27.4 \%)$.

5. All the Ahirwal districts; Mahendergarh (33.3 percent), Rewari (33 percent), Gurgaon (28.8 percent) of Haryana had above state average 27.1 percent. But in terms of gender gap, it was noticeable in Rewari and Mahendergarh (6.2-8.9 percent) 
Table 2.

Haryana, Gender gap at senior secondary education attainment, level in ahirwal districts in 1824 years, age-group 2011

\begin{tabular}{clcccc}
\hline Sr. No. & State/District & Total & Male & Female & Gender Gap \\
\hline $\boldsymbol{0}$ & HARYANA & $\mathbf{2 7 . 1}$ & $\mathbf{2 9 . 3}$ & $\mathbf{2 4 . 6}$ & $\mathbf{4 . 7}$ \\
1 & Mahendragarh & 33.3 & 37.4 & 28.5 & 8.9 \\
2 & Rewari & 33 & 36 & 29.8 & 6.2 \\
3 & Gurgaon & 28.8 & 29.9 & 27.3 & 2.6 \\
\hline
\end{tabular}

Census of India -2011

6. In between Northern and Southern districts there was a belt of districts from Sirsa to Karnal and Panipat through Fatehabad, Hisar, Jind and Kaithal of lower percentage of Senior Secondary Education Attained Female Population. Among these Fatehabad was most backward.

7. Panipat and Karnal were on the G.T. Road still these districts had lower percentage of Senior Secondary Education Attained females.

8. Except Nuh, where Senior Secondary Education Attainment percentage is just eight percent, total population has attained at least 21.9 percent Senior Secondary Education level across the state in all the districts. On looking at male and female population district-wise separately in Haryana excluding Nuh, minimum 23.4 percent male and 16 percent female population has attained Senior Secondary education level in 18-24 years age group.

9. Palwal district has gender gap of 10.9 percent. Nuh 6.7 percent. Lesser gender gap in Nuh does not mean, females of Nuh have attained nearly equal to male Senior Secondary Education, In fact it is nearly one third of male percentage (11.2). Females of Nuh have attained just 4.5 percent.

10. District - wise within male and female populations seperately, high and low Educational Attainment percentages were following nearly same pattern across the state with a difference male population had higher percentage in their district with Yammuna Nagar as exception. (Table and Maps)

11. No district had crossed 32 percent Educational Attainment. Whereas bunch of six district had above 32 percent Senior Secondary Education Attained male population.

\section{Conclusion}

According to 2011 census data, Haryana had wide range of inter-districts variations among Senior Secondary education attained population in total, male and female population as well. Nuh district had the lowest percentage (4.5 percent) among Female Senior Secondary Education attained population. Except Yammunanagar which appeared as star district, though marginally, in terms of attainment of higher percentage of Senior Secondary Educational attainment percentage, females were educationally backward across the state as compared to males at Senior Secondary Education Attainment level in 18-24 years age-group. In Yammunanagr, females were marginally ahead by 0.5 percent. It is evident from data, Yammunagar is not a star district in overall Senior Secondary Education Attainment level. Except Nuh, where Senior Secondary Education percentage was just 8 percent, total population without division in males and female category has attained 21.9 percent Senior Secondary Education level. On dividing male and female population district-wise in Haryana leaving Nuh apart, minimum percentage was at least 16 percent at Senior Secondary education level in 1824 years age-group. All the districts around National Capital Delhi had attained above 27.4 percent. All the Ahirwal districts (Mahendergarh 33.3 percent, Rewari 33 percent, Gurgaon 28.8 percent) of Haryana had shown above state average 27.1 percent. But in terms of gender gap, it was noticeable in Rewari and Mahendergarh (6.2-8.9 percent). In between Northern and 
Southern districts there was a belt of districts with lower percentage of Senior Secondary Education Attained Female Population from Sirsa to Karnal and Panipat. Among these Fatehabad was most backward. Panipat and Karnal were on the G.T. Road still had lower percentage of Senior Secondary Education Attained females.

\subsection{Significance and importance of Study}

The study is a micro level study therefore, it could be used for making comparison with other areas, states of the country. Apart from this, present study will be a study identifying pockets of lower and higher educational attainment among both the gender and overall. 2011 Census Data has been processed and analyzed to find out Senior Secondary education attained persons in the age-group of 18-24 years which is a young age-group. This group looks for jobs. Government also keeps in mind proportion of different levels educationally attained. Therefore, it could be used for planning and management purposes.

\subsection{Limitation of study:}

Only census 2011, district wise, male female wise, age -group data was available therefore this Secondary Data is used as data base.

\section{References:}

Bhende, A. A. \& Kanitkar, T. (2001). Principals of Population Studies, Himalaya Publishing House, Delhi, Pg. 168,174.

Census of India (2011). Registrar General \& Census Commissioner, India.

Government of Haryana (2007). Statistical Abstract, Haryana (20056). Economic and Statistical Adviser, Planning Department, Publication No. 847. Pg.23,29,461,473.

Jayashree (2003). Improvement in Female Life Expectancy. Man and Development journal, December 2003, pg. 910. 